\title{
Norwegian Property and Casualty Insurance Towards 1990
}

\author{
by Jannik Lindbæk *
}

\section{Résumé}

Insurance is in the process of adapting from a product orientated business to a market orientated one. The internal routines must be rearranged. The yield derived from capital today represents a significant part of insurance companies' incomes. The insured has a legitimate right to some of this income. What is now sought is a discussion of the principles involved in such a division.

Competitive ability is equivalent to a sound overall economy. In this article $I$ have turned the spotlight on some of the factors which I feel are essential to competitive ability.

\section{Market orientation}

The traditional insurance industry was product orientated. It was mainly based on a limited range of risks, and a house-owner had to take out a separate insurance for, for example, fire, water pipes, liability, etc. This was an arrangement which was practical for the insurance companies, but was not really suitable for clients.

Even though our product development has become more market orientated, it has taken several years to carry out the necessary organizational adjustments. The comprehensive insurance covers were launched in Norway at the end of the nineteen-fifties, but it was not until the nineteen-seventies that the companies undertook the reorganization which resulted in an internal structure which was adapted to the market.

We are still in the process of changing from a product orientated to a market orientated attitude. The market today demands that the income from capital be divided among the various types of insurance, and, through these, be credited to the insured by the tariff process - an important contribution to the profitability of the various branches of insurance.

For the insurance industry this demand involves an alteration in internal routines. I regard this alteration as a step in the readjustment which began decades ago, with the introduction of the comprehensive covers.

* Managing Director, Storebrand-Norden Group Ltd., Oslo. 


\subsection{The importance of capital investment}

In order to clarify this notion of the importance of capital investment, I shall draw a comparison, taken from the accounts of the Storebrand Group for 1975 and 1981 respectively (before the merger with the Norden Group).

In 1975 the company's premium income for its own account was 711 mill. kroner. In that year the investment income was 66 mill. kroner, corresponding to $9.3 \%$ of the premium for its own account.

In 1981 the premium for its own account had reached 1,835 mill. kroner, and the investment income rose to 255 mill. kroner - $13.9 \%$ of the total premium.

One can see how the relative importance of investment income has become noticeably greater during these six years.

Gradually, as capital innvestment has grown to a certain size, it is natural that both the insurance industry itself and our clients have become concerned about a reasonable division of investment incomes. In the chapter on allocation of investment earnings, I shall examine more closely how a more "just" division of capital investment income can be achieved.

\section{Allocation of investment earnings}

In dividing the capital investment income between the insurance industry and the capital investment industry, an estimated rate of interest calculated on the industry's technical reserves has been stipulated.

However, such a division of investment income has obvious deficiencies :

- The investment income ist not affected by the routines for collection of bad debts.

- Large loss reserves entail a high investment income, which means that a branch with a negative cash-flow can receive a larger share of the investment income than one with a positive cash-flow.

The latter situation makes the idea of investment income for a profit center meaningless if an estimated interest is used, provided it is not seen in connection with the result. If seen in such a connection, a bad technical result can be modified by including the income from the reserves, but this strict interpretation is too easily forgotten, and the reported estimated interest is regarded as income generated from general investment activities. The result of this is, of course, that the division of investment income is not accepted by those responsible for the individual profit centers.

\subsection{Interest on cash-flow}

However, for me, the most important complaint is that the estimated interest is not affected by the routines for the collection of bad debts. Those who are adept at collecting debts should be credited with more interest income, than those who are not. And with today's data systems, calculation of interest directly from cash-flow is possible.

The importance of keeping the cash-fiow under close watch can be illustrated by 
the experience Storebrand obtained during a liquidity project which was undertaken. By simple means we introduced changes which speeded up the cash-flow significantly.

In direct insurance the cash-flow through the company will be almost twice the premium income. In Storebrand-Norden's case it comes to 5 billion Norwegian kroner in 1983. If we manage to make this money "work" on average one day longer, this means - with $15 \%$ yield - ca. 3 mill. kroner.

Therefore it should be obvious that, with a view to profitability, one should operate with actual elements. In other words, the estimated rate of interest must be applied on the liquidity results of the insurance industry, as it actually is. One must differentiate between the accounting result and the liquidity result (cash-flow). If this is not done, the idea of an estimated rate of interest will be meaningless.

Although there is no difficulty in measuring the cash-flow per day for the individual result unit, a number of principal problems remain with regards to the size of the amount of capital - earned in previous years - on which a result unit should be credited interest. As far as I know, there is no generally accepted solution to this problem.

One method would be to use the accumulated cash-flow from earlier years as a basis. If interest is added according to normal rates of interest, this would correspond to the balance of a bank account used exclusively by the result unit. A certain fee to the joint activity would also have to be included, and result units with large fluctuations should be allowed to undertake internal "reinsurance" of the cash-flow. Such an arrangement would entail that a result unit would not be credited interest on technical reserves, but on the accumulated cash-flow, and the greatest problem would be deciding on the starting point.

Actuaries and economists in insurance ought to undertake a discussion of this as soon as possible, with a view to a broader debate of the principles involved in such a division of investment incomes.

\section{The challenges of the approaching 90's}

In the introduction I have dared to suggest that an incorporation of investment income in the technical insurance result is a link in the same development which in its time led to the comprehensive insurance covers.

The market fluctuations and internal administrative routines cannot be allowed to govern how we behave externally.

History tells us that this development will continue. New needs will arise, and the future of the insurance companies in the market today will be dependent on their ability to satisfy these needs, with regard to the adaptation of products and routines to the situation of our overall economy.

\subsection{The state of business}

It is never easy to prophesy new needs. The economic sector is in a very turbulent period, and the last few years have taught us that it is not realistic to count on lengthy 
periods of stable, economic growth. The situation is especially difficult to judge with regards to Norway. In 1982, one third of the State's total tax income came from the oil sector. The standard of living which the oil has generated, has led to a movement in a negative direction in the form of a high cost-level and therefore problems in the domestic based industrial activity. We can see today the contours of a mistaken industrial policy, where subsidies for each place of employment may gradually become unbearable.

The situation is made even more unstable by the fact that the oil income could easily fall due to OPEC's disunity.

\subsection{Insurance - a protected industry}

In this perspective insurance is in many ways a protected industry. The granting of concessions and other public regulations have had the result that we have had little direct competition from abroad in the home market. This situation is now rapidly changing.

An exception here is the marine insurance business, where there is full and open international competition. In this field, Norway, as a shipping nation, has of course represented a special challenge to Norwegian insurance companies. Even though inflation and heavy price competition have worsened the results, the larger Norwegian casualty insurance companies have had few problems compared with many of the country's other industries.

\subsection{Credit evaluation}

The influence on insurance results of the general level of economic activity is, of course, mainly on the investment side. We are dependent on the Norwegian customers. Insurance has always placed stringent demands on debt security and traditionally both casualty and life insurance companies have had very few losses on the investment side.

Doubt can be raised about whether the traditional mortgaging of loans today gives real security. The mortgage value of industrial complexes outside the urban areas, are often only a fraction of the cost price. In the last few years there has been in Norway a significant political pressure on creditors in connection with bankruptcies.

The "modern bankruptcy" where creditors are threatened with being held responsible for the unemployed workers has brought new ideas into the assessment of an investment risk. And, to a much greater degree than before, we shall be forced to undertake an assessment of credit based on an industry's expected future potential - not on its "slaughter value".

The distinction between the investment yield accruing to the insured and the investment yield from a company's own capital, creates new demands for reassessment of investment strategy. In order to secure a certain calculated interest the means concerned must be invested in bonds with a continuous yield and good security. The result would be a turning away from both property and high risk projects. 


\section{4. "All I want in life is an unfair competitive advantage"}

The head of the American Insurance Group is said to be the man behind the above expression. This is something we could all wish for insurance company's economy. In the long term, competitiveness is equivalent to profitability, and an assessment of a company's economic development can only be made in connection with an appraisal of the ability to compete in the markets in which the company operates.

In this sense, the Norwegian insurance market is in a rapid state of change. The competitive situation of the 1970's has been dramatically changed by the merger of Storebrand and Norden, mainly from the abolition of the tariff agreement, to the cooperation agreement between Norges Brannkasse and Norske Folk. So far, the contours of at least four powerful insurance groups can be seen in the period up to 1990 . In addition we must expect an increasing influx of foreign competition directed at the large Norwegian industrial companies.

\subsection{Clients}

In the future there will still be many different groups of clients on the market. One important part of marketing will, of course, consist of a successful division into segments, but, typically, the affluent groups will probably be both quality and price conscious. These clients will demand :

- a high standard of service,

- total risk solutions and

- extended product range with more weight placed on risk reduction/loss prevention.

\subsection{Product range}

Regarding the product range, we must assume that insurance will, in many ways, follow in the footsteps of banks. Only 10 years ago, the banks' services were advertised as saving with 3,6 or 12 months cancellation. Nowadays, the various accounts are suited to the groups of clients, and the range of services is extended to include, amongst others, property sales and stockbroking. The insurance industry in Norway has just begun to incorporate activities which do not fall inside the traditional areas of business.

The market expects us to perform a service which includes more than the sale of insurance and claims management. It is quite natural for us to become more strongly engaged in loss prevention including, among other things, the sale of security products. Consultant services, based on risk management, are also a result of an adaptation to new needs and the market.

\subsection{Competition for technology}

The development of dataprocessing is a key factor in the competition. Many of the client's demands will be connected to the technological level, and the company which succeeds in this field also has the advantage that it takes time to copy technical solutions. Already today, larger clients wish to be connected to EDU's in order to get 
information regarding their own portfolio. New account arrangements, with automatic remittance and oportunities for loans, are also in the pipeline. A rigid data system will be unable to solve this type of problem satisfactorily, and great demands will be placed on the future development.

Storebrand-Norden have, at present, over 1,000 EDU's in our more than 100 offices in Norway. Therefore decentralization is possible, and we have come closer to the client both in policy and claims management. Even though we have already gone through the "terminalisation process", it is obvious that the development which we have witnessed, is only the beginning of a series of fundamental changes.

As the data processing system can be used as an intelligent assistant, the possibilities for innovation and new thinking are almost unlimited. The insurance company which manages to administer this process optimally will have won the fight for competitiveness in a very important field.

The development of dataprocessing is very expensive. One way to cover the costs, and simultaneously raise the internal level of knowhow, is to sell insurance software to others. With the level now prevailing in Scandinavia, with regard to the use of data technology, extensive international insurance markets will be potential buyers of our systems. There are many dangers, and there is obviously a significant possibility of failure in selling software internationally, but one thing is certain : If we are to succeed it must be done professionally.

\section{Need for increased efficiency}

In a market with a handful of active competitors, the individual company's strategy will be based on specific assumptions of the future plans of the other companies in the market. So far, we have in Norway experienced this competition as "fair" and we are obviously on the threshold of an interesting period. The danger involved in this situation is "shortsightedness". We measure ourselves against our own " mirror image" forgetting to question the fundamental structures under which we operate. Competition, in the form of new insurers in the market, can be a big surprise in such a situation.

The insurance companies in Norway have a marketing system with a unique geographical spread. On a domestic basis, this provides an opening to the market which no others can equal. Therefore, the efficiency in this field must not be judged on the basis of the existing competitive situation.

If the industry should not manage to master the distribution costs better than today, we must expect new groups to include insurance in their range of products. Such a development can only be avoided by making the market operate more efficiently, and, consequently, it is necessary to examine critically the industry's operating costs generally and distribution costs in particular, with regard to the overall economic situation. 